\title{
EDITORIAL
}

\section{Tuberculosis control programme from NTCP to RNTCP to NTEP}

\section{Ashok Kumar Bhardwaj}

Chairman Zonal Task Force on NTEP, North Zone, Professor and Head, Community Medicine, Dr. Radhakrishnan Govt. Medical College, Hamirpur, Himachal Pradesh

\section{Corresponding Author}

Dr. Ashok Kumar Bhardwaj, Chairman, Zonal Task Force on NTEP, North Zone, Professor and Head, Department of Community Medicine, Dr. Radhakrishnan Govt. Medical College, Hamirpur, Himachal Pradesh - 177001

E Mail ID: ashoknonu@gmail.com

\section{Citation}

Bhardwaj AK. Tuberculosis control programme from NTCP to RNTCP to NTEP. Indian J Comm Health. 2020;32(3):469-470.

\section{Article Cycle}

Received: 21/07/2020; Revision: 15/08/2020; Accepted: 28/08/2020; Published: 30/09/2020

This work is licensed under a Creative Commons Attribution 4.0 International License.

India, the highest TB burden country in the world, is having an estimated incidence of 26.9 lakh cases in 2019 (WHO). The year 2019 marks another milestone year for TB surveillance effort in India, with a record high notification of 24 lakhs cases; an increase of over $12 \%$ as compared to 2018. Of the 24 lakhs TB cases,(1) 21.6 lakhs were incident TB cases (New and Relapse/ Recurrent). This amount to an incident notification rate of approximately 159 cases/lakh against the estimated incidence rate of 199 cases/lakh population; thus, closing the gap between the estimated and notified incident cases to just 40 Cases per lakh population, or an approximate of 5.4 lakh missing cases across India.

The India's Tuberculosis (TB) control programme got rechristened to National Tuberculosis Elimination Programme (NTEP) from Revised National Tuberculosis Control Programme (RNTCP) on January 1st, 2020.

The longest battle against this disease in India started as National TB Control Programme (NTCP) in 1962 and continued with two phases of RNTCP from 1997 through 2019. The estimated incidence of TB in India in 2019 was 199 per lakh population.(1) India is home to the world's quarter of TB cases.

As a first step in the country for TB control, TB Association of India (TAI) was established in 1939 to develop standard methods for managing TB and to develop model training institutions.(2) In 1959 the Government of India, with the help of World Health Organization (WHO), established the National TB Institute (NTI) in Bangalore to develop a National TB Control Programme (NTP). The aim was to establish prompt diagnosis and ambulatory treatment. NTCP initiated in 1962 was originally designed for domiciliary treatment, using self-administered standard drug regimens. Short course chemotherapy was introduced from 1983 in the programme but compliance improved only marginally.(2)

The review of NTCP in 1992 highlighted managerial weaknesses, the over-emphasis on X-rays for diagnosis, underutilization of laboratory services, frequent drug shortages, and low rates of treatment completion. Hence Government of India decided to revitalize NTCP with the assistance of international agencies.

In 1997, the RNTCP was launched as a national programme and scaled it up in a phased manner. The RNTCP was designed to deliver TB services through the general health service infrastructure, building on the network developed by the NTCP. The programme was based on DOTS (Directly Observed Treatment Short course) which promotes diagnosis by sputum smear microscopy, direct observation of treatment, standardized regimens, recording and reporting of notified cases and treatment outcomes, and above all political and bureaucratic commitment.(3) Treatment outcomes under the RNTCP were already quite good in 1994 and continued to improve up to 2006, reaching the target of $85 \%$ treatment success in 2001 . Unfavorable outcomes fell and have remained consistently below $15 \%$ since 2001.(1)

On the managerial front the TB programme management units, both at the national and state levels; have been embedded right from inception within the respective health ministries and the directorates of health services. The TB programme became a part of the National Health Mission since 2005.

Since TB became a notifiable disease in 2012, private providers nationwide have notified more than 0.7 million TB patients.(4) The national programme also initiated an innovative and visionary electronic recording and reporting system (Nikshay) across the country in 2012, with $98 \%$ of reporting units sending in case based reporting of TB patients, including notifications from private providers.(4) From 2014 onwards universal Drug Sensitivity Testing is being offered to notified TB patients (both public and private sector) to assess the presence of Rifampicin resistance at the time of TB diagnosis. 
The global public health and TB community is shifting its focus from control of the TB epidemic towards elimination. It is India's success that will determine the global progress towards ending TB and subsequently elimination. The National Strategic Plan (NSP) 2017-2025 was set up under the Revised National Tuberculosis Control Program (RNTCP). The stated aim is complete elimination of the disease by 2025 . The requirements for moving towards TB elimination have been integrated into the four strategic pillars of "Detect - Treat - Prevent Build" (DTPB).(4)

India has committed to END TB and is at a critical stage with the national momentum expected to accelerate after the increased political commitment and heightened community awareness about public health and hygiene and the threat of communicable disease following the COVID-19 pandemic. Hence this NSP to END TB (20202025) seizes this opportunity to collaborate intensively with various ministries to promote a multi-sectoral response to END TB while continuing to implement the program and deliver impact.

The global incidence rate needs to be falling by $4-5 \%$ every year to meet the first milestone of the End TB strategy; a $20 \%$ reduction by 2020 (compared with 2015). Only the countries located in central Europe or Latin America and the Caribbean have shown a decline $>5 \%$ per year, are mostly those that are islands, have a high average income.(5) Since 2016, India's TB incidence has dropped by a mere 1.7 percent annually.

The Government expenditure on health for decades has been one of the lowest in the world at $1.4 \%$ of the GDP.(6) In 2017 Union Budget additional funding for health has been allocated, but this will substantially fall short of the $2.5 \%$ of the GDP that has been considered a realistic goal in the National Health Policy 2015.(7) RNTCP has also struggled to receive funding that is proportionate with the scale of India's epidemic.(8) There was anticipation of a tripling of the budget for the period 2012-2017, but this did not happen.

The private sector in India currently handles about $28 \%$ of India's 2.4 million new TB cases every year(1) and $42 \%$ out of all pediatric TB cases reported in the country. Most patients in Indian cities make private clinics as the first point of treatment.(9)

Bedaquiline has been developed as a "last resort" solution for drug-resistant TB patients as per WHO guidelines. Despite widespread drug resistant TB, only 27 percent of India's TB patients qualify for treatment with this medicine. This is the only new drug that has come up after decades of anti tubercular drug discovery. This calls for research to focus on development and/or validation of new tools, including rapid point of care diagnostics, new TB drugs and vaccines.(10)

The social stigma, lack of medication, lack of awareness, and unaffordable medical care are the major hindrances in decreasing the burden of Tuberculosis in India. These are the major determinants of large gap in ambition and reality. The policy makers and the researchers have to understand that the social determinants along with diagnostic and treatment play a major role in achieving the elimination goal.

All TB workers are working overtime in pressured and challenging situations during the current COVID-19 pandemic to provide services to patients. Despite these intensive efforts, most healthcare systems are struggling with resource limitations and commitment towards COVID pandemic.

All of us are being stressed; none of us is going to escape the expected. The expected strategies might have exhausted, we are surely going to find our own pattern of continuum of care to TB patients during this COVID pandemic that works best everyday and every moment. However, intervening with the social determinants in a country like India which took 100 years to bring in "Swachh Bharat Mission" is a challenge in its own.

The composure of TB workers, their self-efficacy, social connect, togetherness as fraternity and faith have raised the hope that, we shall overcome...

\section{References}

1. Government of India. Ministry of Health and Family Welfare. Central TB Division. India TB Report 2020. National tuberculosis programme. Annual Report. MOHFW. New Delhi. March 2020.

2. Agarwal SP, Chauhan LS, Tuberculosis Control in India, New Delhi, Directorate General of Health Services, Ministry of Health and Family Welfare, 2005.

3. Raviglione MC, Pio A. Evolution of WHO policies for tuberculosis control, 1948-2001. Lancet. 2002 Mar 2;359(9308):775-80. doi: 10.1016/s0140-6736(02)07880-7. PubMed PMID: 11888605.[PubMed]

4. Government of India. Central TB Division. MOHFW. National strategic plan for TB elimination 2017-25. Director General Health Services. MOHFW. New Delhi. March 2017.

5. Dye C, Lönnroth K, Jaramillo E, Williams BG, Raviglione M. Trends in tuberculosis incidence and their determinants in 134 countries. Bull World Health Organ. 2009 Sep;87(9):683-91. doi: 10.2471/blt.08.058453. PubMed PMID: 19784448; PubMed Central PMCID: PMC2739916. [PubMed]

6. The Lancet. Health in India, 2017. Lancet. 2017 Jan 14;389(10065):127. doi: 10.1016/S0140-6736(17)30075-2. Epub 2017 Jan 13. PubMed PMID: 28102123.[PubMed]

7. Ministry of Health and Family Welfare. National Health Policy 2017. In: India Go. New Delhi, India: Government of India, 2015. http://www.mohfw.nic.in/showfile.php?lid=3014 (accessed 12 May 2019).

8. Babu R, Sagili K, Jacob A, et al. Resource optimisation for tuberculosis elimination in India. Econ Political Wk 2016; L1:26-7.

9. Arinaminpathy $N$, Deo $S$, Singh $S$, Khaparde $S$, Rao R, Vadera $B$, Kulshrestha N, Gupta D, Rade K, Nair SA, Dewan P. Modelling the impact of effective private provider engagement on tuberculosis control in urban India. Sci Rep. 2019 Mar 7;9(1):3810. doi: 10.1038/s41598-01939799-7. PubMed PMID: 30846709; PubMed Central PMCID: PMC6405912.[PubMed]

10. Pai M, Bhaumik S, Bhuyan SS. India's plan to eliminate tuberculosis by 2025: converting rhetoric into reality. BMJ Glob Health. 2016;2(2):e000326. doi: 10.1136/bmjgh-2017-000326. eCollection 2016. PubMed PMID: 28589035; PubMed Central PMCID: PMC5435272.[PubMed] 